\title{
Nitrate utilization and nitrogen status in English woodland communities
}

\author{
E.C.M. Clough, J. Pearson and G.R. Stewart
}

Department of Biology (Darwin), University College London, Gower Street, London WC1E 6BT, U.K.

\section{Introduction}

There have been few studies of nitrogen (N) assimilation in perennial woody species. The present study shows that leaf nitrate reduction is of common occurrence in woody plants of English woodland communities. Pioneer species tend to exhibit a greater capacity for leaf nitrate reduction than climax species. Seasonal profiles of leaf nitrate reductase (NR) activity show that the enzyme activity varies throughout the year, with flushes of activity occurring in most species in spring, when the buds of deciduous species are beginning to break. Amino acid analyses show that glutamate and alanine concentrations increase as NR activity increases, whereas asparagine was found to decrease.

\section{Materials and Methods}

Three woodland sites were sampled: Bencroft Wood in Hertiordshire, Boxhill in Surrey and Tooting Graveney Common in London. A large number of tree species were regularly assayed for leaf NR activity (for in vivo assay method see Smirnoff et al., 1984) between October 1987 and September 1988. Free amino acids were analysed by standard HPLC techniques.

\section{Results and Discussion}

Fig. 1 compares the frequency distribution of NR activity in leaves of woody species in the temperate woodlands at Boxhill and Bencroft Wood with leaf NR activity at Brigalow, a tropical forest in Australia (data from Stewart et al., 1988). The growth of plants in many ecosystems is restricted by the availability of $N$. In forests, uptake occurs primarily from the surface soil organic layer. In tropical forests, however, a zone of organic accumulation typically does not develop because of high rates of decomposition, meaning that there is no consistent supply of inorganic $\mathrm{N}$ in the soil solution. The low concentration and supply of the enzyme substrate nitrate in the ancient tropical soils results in low NR activities (see Fig. 1c). Over $80 \%$ of the tropical species assayed by Stewart et al., (1988) had activities less than 100 pkat $\cdot g^{-1}$ fwt, with few species having activ- 


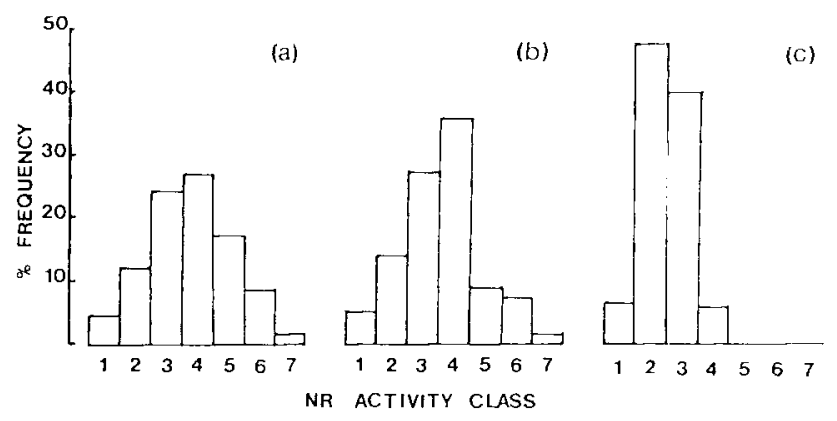

Fig. 1. Frequency distribution of nitrate reductase activity in the leaves of woody plants growing in English and Australian woodlands. (a) Boxhill; (b) Bencroft Wood; (c) Brigalow. NR activity classes: 1, <25; 2, 26-50; 3, 51-100;4, $101-250 ; 5,251-500 ; 6,501-1000 ; 7,>1000$ pkat $\cdot g^{-1}$ fwt.

ities in classes 5, 6 and 7. In contrast, the English woodland communities (Fig. 1a, b and Tooting Graveney Common (data not shown)) show a wide range of nitrate reductase activities normally distributed about the mean values, indicating a more varied supply of inorganic $\mathrm{N}$ than is found in tropical soils.

It was found that the highest rates of leaf nitrate reduction were present in the pioneer species characteristic of the early stages of forest growth (see Fig. 2). The pioneer species Sambucus nigra (elder)

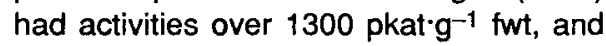
over $50 \%$ of all pioneer species sampled had activities in excess of 250 pkat $\mathrm{g}^{-1}$ fwt. In contrast, the climax species at the sites (e.g., Fagus sylvatica (beech) and Quercus robur (oak)) were generally of low activity. At Bencroft Wood and Boxhill over $50 \%$, and at Tooting Graveney Common $67.5 \%$ of climax species had activities less than 100 pkat. $\mathrm{g}^{-1}$ fwt. Climax species on the 3 sites had an average NR activity of only 117 pkat $\cdot \mathrm{g}^{-1}$ fwt compared with 340 pkat $\mathrm{g}^{-1}$ fwt for pioneer species. Generally speaking, NR is a substrate inducible enzyme. The variation in activity observed between pioneer and climax species suggests that more of the sub-

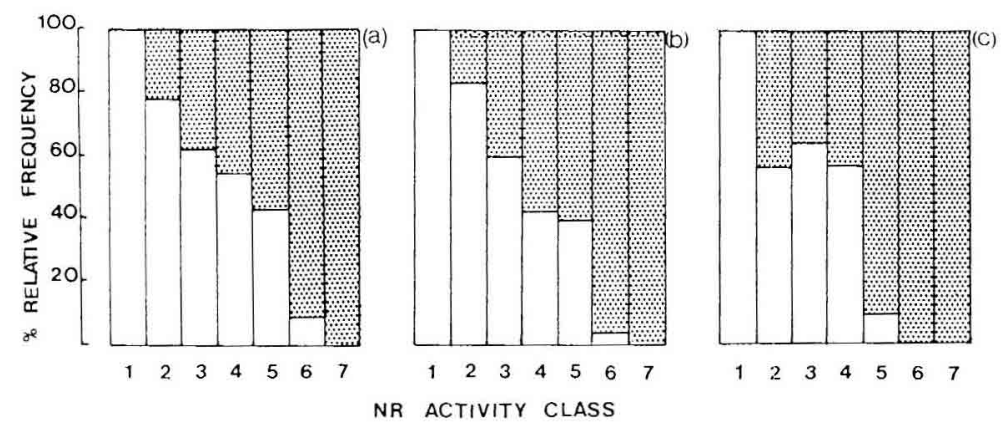

Fig. 2. Percent relative frequency distribution of nitrate reductase activity in the leaves of climax and pioneer species. (a) Bencroft Wood; (b) Boxhill; (c) Tooting Graveney Common. $\square$ : climax species; 国 : pioneer species. 
strate nitrate is available in areas of disturbance and regrowth where pioneers grow. The low levels of expression of NR activity in species of closed climax communities suggest that they utilize $\mathrm{N}$ sources other than nitrate. Species of the closed forest are plants that, for the most part, utilize ammonia ions or organic $\mathrm{N}$, both root located processes (Raven, 1985). Energetic considerations suggest that leaf assimilation carries a lower energy cost than root assimilation (Stewart et al., 1986) and, in environments where competition for nutrients and shading are minimal, leaf assimilators may predominate. Conversely, shade species will have little energetic advantage in leaf assimilation, since photosynthesis will be lightlimited. The restriction of assimilation to roots may allow greater control over the use of limited light between $\mathrm{N}$ and carbon assimilation (Smirnoff and Stewart, 1985). In the present study, only leaf NR activity has been examined. Investigations of root activities in English woodland species have yet to be carried out.

Many species were analysed for seasonal variations in NR activities. The results for 4 species are presented in Fig. 3. A spring flush was apparent in elder between April and May, after which a steady decline in activity continued until Septem- ber. In February-March, elder was one of the few woody plants in leaf and, since nitrate reduction in green leaves is essentially dependent upon photosynthesis, the very high activity in March could be due to high light availability in the absence of a canopy. Oak and hornbeam (Carpinus betulus) showed approximately simultaneous budbreak $(\boldsymbol{\nabla})$, after which NR activity increased with leaf expansion. Senescence began in July-August, and the activity declined to low levels until the end of the winter. Flushes of activity observed during the winter may be due to the utilization of $\mathrm{N}$ accumulated earlier in the season to sustain growth over the winter period. Holly (llex aquifolium), an understorey shrub, initially followed a pattern of NR activity similar to oak, hornbeam and beech (data not shown), but throughout the summer and autumn the activity in holly steadily increased. In late summerearly autumn, the competition for light and nutrients is reduced as the deciduous canopy declines, and it is this reduction in competition which is likely to be the reason for the late flush of activity in the evergreen holly. Apart from seasonal variations in activity, a number of workers have reported that diurnal variations exist. Significant seasonal fluctuations in soil nitrification are also possible.
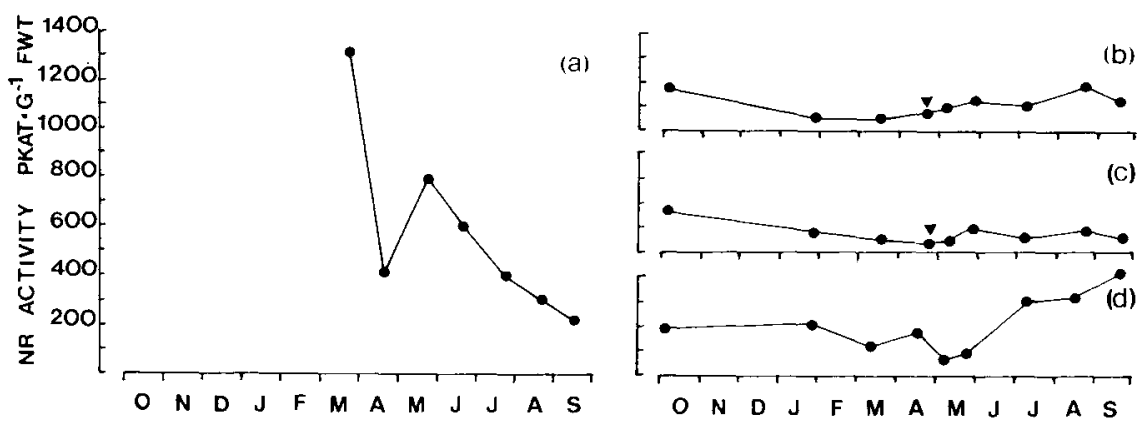

Fig. 3. Seasonal variation in nitrate reductase activity in the leaves of 4 species growing in Bencroft Wood: (a) elder, (b) oak, (c) hornbeam, (d) holly. 
Some trends were observed in amino acid concentrations in relation to leaf NR activity (see Fig. 4). Asparagine concentration decreased as NR activity increased. Some woody plants low in leaf NR activity have been found to be active in root assimilation of nitrate and transport $\mathrm{N}$ from root to shoot in the form of asparagine (e.g., Stewart et al., 1987). The concentration of asparagine might be higher in the lower leaf NR classes, since more nitrate reduction is occurring in the roots of these plants and asparagine is being employed as the transport compound. It has also been shown that NR activity can be repressed in some plants by end-products, such as ammonia and amino acids (e.g., Stewart, 1972). The low activities in classes 1,2 and 3 could be due to inhibition by high concentrations of asparagine. Both glutamate and alanine increased as leaf NR activity increased. Rhodes et al. (1976) found that glutamate and alanine pools increased in Lemna minor as nitrate concentration increased. When rice seedlings were grown on $15 \mathrm{~N}$ labelled $\mathrm{KNO}_{3}$ solution (Yoneyama and Kumazawa, 1975), it was found that the most highly labelled amino acids in the

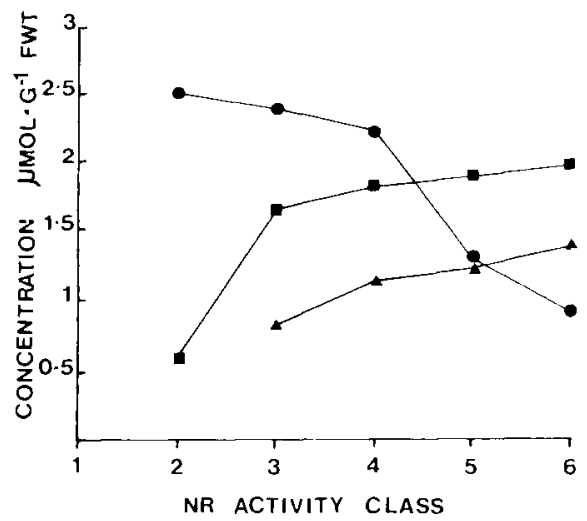

Fig. 4. Amino acid levels in woody plants: (A) alanine; (O) asparagine; ( $\mathbf{\square}$ glutamate. shoots were alianine and glutamate. This could infer, therefore, that where there is an adequate supply of nitrate (i.e., in the higher activity classes), higher concentrations of alanine and glutamate may be found, whereas in areas where nitrate supply is limited (i.e., in climax communities exhibiting low activities of NR), comparatively low concentrations of glutamate and alanine exist.

\section{References}

Raven J.A. (1985) Regulation of $\mathrm{pH}$ and osmolarity generation in vascular land plants; cost and benefits in relation to efficiency of use of water, energy and nitrogen. New Phytol. 101, 25-77

Rhodes D., Rendon G.A. \& Stewart G.R. (1976) The regulation of ammonia assimilating enzymes in Lemna minor. Planta 129, 203-210

Smirnoff N. \& Stewart G.R. (1985) Nitrate assimilation and translocation by higher plants: comparative physiology and ecological consequences. Physiol. Plant. 64, 133-140

Smirnoff N., Todd P. \& Stewart G.R. (1984) The occurrence of nitrate reduction in the leaves of woody plants. Ann. Bot. 54, 364-374

Stewart G.R. (1972) The regulation of nitrate reductase level in Lemna minor L. J. Exp. Bot. 23, 171-183

Stewart G.R., Hegarty E.E. \& Specht R.L. (1988) Inorganic nitrogen assimilation in plants of Australian rain forest communities Physiol. Plant. 74, 26-33

Stewart G.R., Popp M., Holzapfel I., Stewart J.A. \& Dickie-Eskew A. (1986) Localization of nitrate reductase in ferns and its relationship to environment and physiological characteristics. New Phytol. 104, 373-384

Stewart G.R., Surnar N. \& Patel M. (1987) Comparative aspects of inorganic assimilation in higher plants. Ir: Inorganic Nitrogen Metabolism. (Ulirich et al.. eds.), Springer-Verlag, Berlin

Yoneyama T. \& Kumazawa K. (1975) A kinetic study of the assimilation of $15 \mathrm{~N}$-labelled nitrate in rice seedlings. Plant Cell Physiol. 16, 21-26 